\title{
Interactive comment on "Power curve and wake analyses of the Vestas multi-rotor demonstrator" by Maarten Paul van der Laan et al.
}

\section{Anonymous Referee \#2}

Received and published: 8 February 2019

The paper describes a comparison between measurements and simulations of wakes of the multi-rotor demonstrator at Risø. The paper is thorough, but unfortunately measurements and simulation results do not match up. Good to publish though, for other's to improve upon further.

\section{Some questions:}

- Does the influence of trees and highway (mentioned on page 6., line 10) perhaps explain some of the differences between measurement and simulation (far wake)?

- On page 7, line 9-11, it is stated that the atmospheric conditions were used as input to the simulations. Yet on page 18 line 11-13, it is stated that the near-neutral conditions could have reduced wake deficit of measurements relative to simulations. How can the 
conditions still be "blamed" if they were taken into account in the simulations, also the more high-fidelity ones? Am I missing something?

WESD

Possible correction: - Page 18, line 7-8: Isn't wake deficit higher if wind speed is lower in the wake?

Interactive comment on Wind Energ. Sci. Discuss., https://doi.org/10.5194/wes-2018-77, 2019.

Interactive

comment 